\title{
Nanoreactor Effect in Bifunctional Cation Exchangers Based on Cis-Metacyclophanoctol
}

\author{
Heinrich Altshuler ${ }^{1}$, Olga Altshuler ${ }^{2}$ \\ ${ }^{1}$ Institute of Coal-chemistry and Material Science, Siberian Branch of Russian Academy of Sciences, 650000, \\ Kemerovo, Russian Federation \\ altshulerh@gmail.com \\ ${ }^{2}$ Kemerovo State University, 650043, Kemerovo, Russian Federation \\ colo@list.ru
}

\section{ABSTRACT}

The nanoreactor effect consisting in sufficiently high rate increase of a cation diffusion flux in bifunctional cation exchangers based on cis-metacyclophanoctol has been found. The solutions of the fundamental differential equation of cation diffusion in bifunctional cation exchangers containing sulfonic acid and phenol ionogenic groups by means of the spherical layer and plane sheet models are presented for a variety of initial and boundary conditions with constant diffusion coefficient.

\section{Keywords}

Bifunctional cation exchangers, cis-metacyclophanoctol, diffusion flux, nanoreactor effect.

\section{Academic Discipline And Sub-Disciplines}

Physical chemistry; nanochemistry

\section{TYPE (METHOD/APPROACH)}

Theoretical and Experimental

\section{Council for Innovative Research}

Peer Review Research Publishing System

Journal: Journal of Advances in Chemistry

Vol. 7, No. 2

editor@cirworld.com

www.cirworld.com, member.cirworld.com 


\section{INTRODUCTION}

A nanoreactor is a nanosized container used for accommodating chemical reactions [1]. Nanoreactor increases the rate of diffusion with respect to bulk reaction due to the short pathway that reagent molecules need to follow to meet each other [1]. Cis-metacyclophanoctol molecule consisting of great hydrophobic cavity and the upper hydrophilic rim including eight hydroxylic groups [2] is a typical nanoreactor. Especially it is true for reactions associated with the self-assembly mechanism of proton transfer within the molecule [3].

New network functional polymers were synthesized by connection of cyclophanoctols to cross-linked polysterene matrix [4], by catalytic resol polycondensation of cis-tetramethylmetacyclophanoctol or cis-tetraphenylmetacyclophanoctol with formaldehyde [5-8]. Immobilized cis-metacyclophanoctol derivatives were proposed as nanoreactors for catalytic hydrogenation processes [9] and cation exchangers [5,10,11]. The structure of an elementary unit (Figure 1) of network polymers received by polycondensation of cis-metacyclophanoctol derivatives with formaldehyde is given in [7].

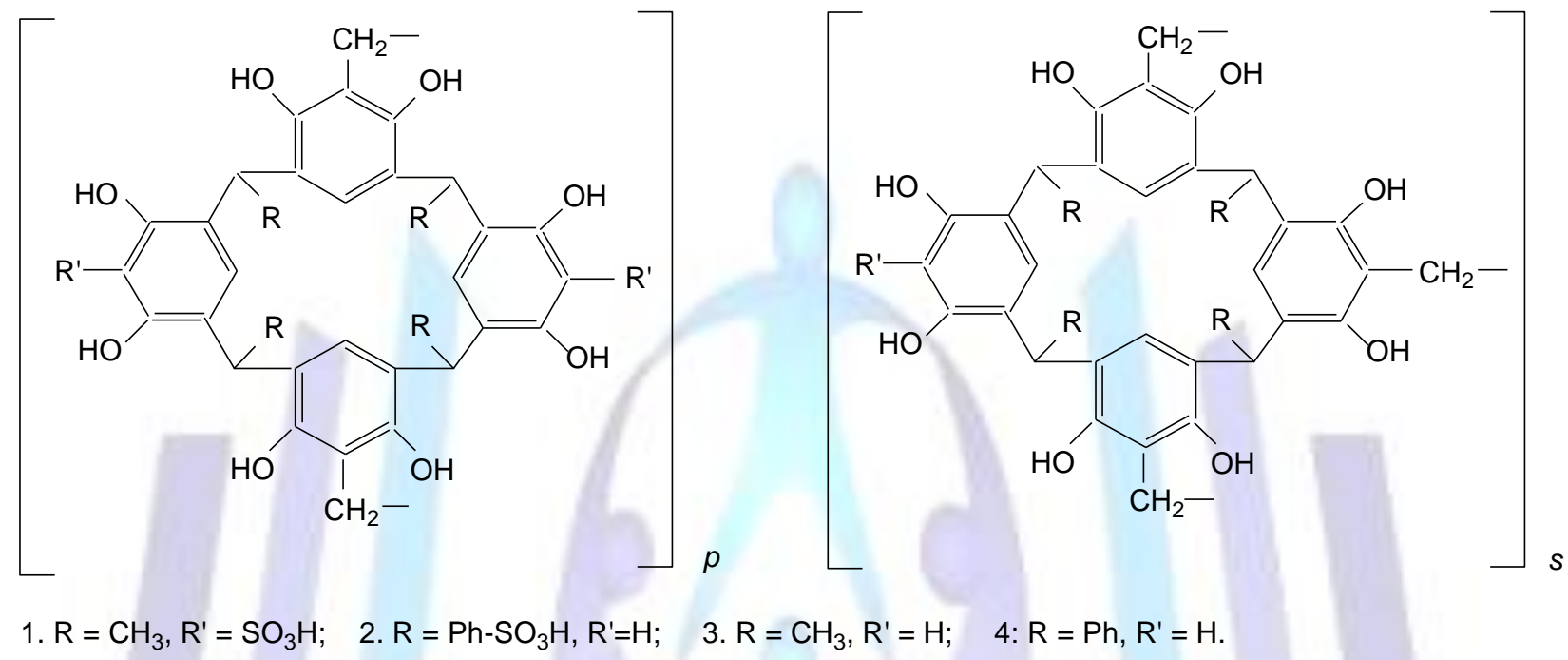

Fig 1: An elementary unit of network polymers based on cis-metacyclophanoctol derivatives

As was previously reported in [7], bifunctional polymers 1 and 2 contain strongly acidic $\mathrm{SO}_{3} \mathrm{H}$ groups which dissociate with the formation of free protons over a wide $\mathrm{pH}$ range (0-14), and weakly acidic phenol $\mathrm{OH}$ groups. Monofunctional polymers 3 and 4 , include only weakly acidic phenol $\mathrm{OH}$ groups. The thermodynamics and kinetics of ion exchange in polymers 1 - 4 based on cis-metacyclophanoctol were investigated in [12-16]. It was shown [14-16] that the limiting stage of ion exchange kinetics is diffusion of ions in the polymers.

The purpose of the present work is mathematical description of cation flux in bifunctional polymers containing strongly and weakly acidic groups, particularly in bifunctional sulfonated polymers 1 and 2 based on cis-metacyclophanoctol.

\section{MATERIAL AND METHODS}

\subsection{Synthesis}

Polymer 1 and 2 were produced by sulfonatation of monofunctional polymers 3 and 4 on according to the procedure [8]. The total dynamic ion-exchange capacities (in equiv. per $1 \mathrm{~kg}$ of the polymer in the $\mathrm{H}$ form dried at $105^{\circ} \mathrm{C}$ of the polymers) were 6.0 and 5.65 for polymers 1 and 2 respectively. The contents of acidic $\mathrm{SO}_{3} \mathrm{H}$ groups in polymers 1 and 2 were 1.86 and 2.45 equiv. per $1 \mathrm{~kg}$ of the dry $\mathrm{H}$ form of polymer.

\subsection{Kinetic studies}

For kinetic studies the selection of spherical granules and the determination of their sizes were performed using the IMTs $100 \times 50$, A microscope. Polymer granule size distribution corresponded to a normal (Gaussian) distribution. The particle radius calculated as an arithmetic average of the size of 1000 spherical granules was $(1.02 \pm 0.53) \cdot 10^{-4} \mathrm{~m}$.

The kinetics of ion exchange was studied by the dynamic thin-layer method [17] at $298 \mathrm{~K}$ by sorption from an infinite volume of electrolyte solutions with concentrations of $0.01,0.03,0.05$ and $0.1 \mathrm{~mol} / \mathrm{dm}^{3}$.

\subsection{Calculation details}

Molecular structure of the repeating unit of polymers was optimized in terms of enthalpy of formation by the semiempirical PM6 method within the MOPAC 2009 program, ion exchange kinetics and diffusion coefficients were calculated by iteration method within the MathCad 7 program. All calculations are fulfilled on Intel (R) Core(TM)2 Duo T7300 processor. 


\section{THEORY}

\subsection{Ion exchange processes}

The following ion exchange processes take place in bifunctional polymers 1 and 2 :

with participation of sulfonic acid groups

$$
\mathrm{HO}-\mathrm{L}-\mathrm{SO}_{3}^{-} \mathrm{H}^{+}+\mathrm{Cat}^{+} \rightarrow \mathrm{HO}-\mathrm{L}-\mathrm{SO}_{3}^{-} \mathrm{Cat}^{+}+\mathrm{H}^{+}
$$

with participation both sulfonic acid and phenol $\mathrm{OH}$ groups

$$
\mathrm{HO}-\mathrm{L}-\mathrm{SO}_{3}^{-} \mathrm{Cat}^{+}+\mathrm{Cat}^{+}+\mathrm{OH}^{-} \rightarrow \mathrm{Cat}^{+} \mathrm{O}^{-}-\mathrm{L}-\mathrm{SO}_{3}^{-} \mathrm{Cat}^{+}+\mathrm{H}_{2} \mathrm{O} .
$$

Here L - fragment of elementary unit of polymer based on cis-metacyclophanoctol.

In bifunctional polymers 1 and 2 it is possible to obtain phenolate $\mathrm{L}_{-} \mathrm{O}^{-} \mathrm{Cat}^{+}$as a sum of processes (I) and (II). In monofunctional polymers 3 and 4 ion exchange process (III) take place only with phenol OH groups.

$$
\mathrm{HO}-\mathrm{L}+\mathrm{Cat}^{+}+\mathrm{OH}^{-} \rightarrow \mathrm{Cat}^{+} \mathrm{O}^{-}-\mathrm{L}+\mathrm{H}_{2} \mathrm{O} .
$$

To choose the optimal technique of obtaining of phenolate of $\mathrm{Cat}^{+} \mathrm{O}^{-} \mathrm{L}$ it is necessary to compare the rates and mechanisms of processes (I) - (III).

\subsection{Fundamental diffusion equation}

The fundamental diffusion equation (1) in the case of constant diffusion coefficient and spherical symmetry is applied [18] if diffusion of ions in polymers is rate limiting stage of ion exchange

$$
\frac{\partial C}{\partial t}=D\left(\frac{\partial^{2} C}{\partial r^{2}}+\frac{2}{r} \frac{\partial C}{\partial r}\right)
$$

Where $D$ - diffusion coefficient of the species; $C$ - current concentration of the species in a polymer; $r$ - radius-vector; $t-$ time. Let us consider the solution of equation (1) for processes (I) - (III).

\subsection{Solution of the diffusion equation for cation exchange process (I) in polymers 1 and 2 with participation of sulfonic acid groups}

Early we investigated [15] the kinetics of cation exchange process (I) with participation of sulfonic acid groups of polymers 1 and 2. The expression

$$
F=\frac{M_{t}}{M_{\infty}}=1-\frac{6}{\pi^{2}} \sum_{n=1}^{\infty} \frac{1}{n^{2}} \exp \left(-D_{w} n^{2} \pi^{2} t / r_{0}^{2}\right)
$$

for the transformation degree $(F)$ of ion exchanger [17] describes experimental data for exchange of protons by metal cations from $\mathrm{SO}_{3} \mathrm{H}$ groups of polymers [15]. Here, $M_{t}$ - the amount of cations sorbed at time $t ; M_{\infty}$ - equilibrium ion exchange capacity; $D_{w}$ - effective diffusion coefficient in polymer, $r_{0}$ - average radius of spherical particle of polymer. The values of effective diffusion coefficient of cations in sulfonated polymer 2 based on cis-tetraphenylmetacyclophanoctol, calculated with probability 0.9 by equation (2), are in the $(1.9 \div 2.1) \cdot 10^{-11} \mathrm{~m}^{2} / \mathrm{s}$ interval.

\subsection{Solution of the diffusion equation for cation exchange process (II) in polymers 1 and 2 with participation both sulfonic acid and phenol $\mathrm{OH}$ groups}

Before the beginning of process (II) bifunctional polymers 1 and 2 already contain $\mathrm{Cat}^{+}$whose concentration is equal to that of $\mathrm{SO}_{3}^{-}$groups. In process (II) the ion exchange of protons of phenol $\mathrm{OH}$ groups by Cat ${ }^{+}$takes place. The rate of process (II) with participation of polymers 1 and 2 is controlled by $\mathrm{H}^{+}$and $\mathrm{Cat}^{+}$interdiffusion in a spherical particle of a polymer.

\subsubsection{Effective diffusion coefficient}

According to diffusion mechanism of process (II) for constant diffusion coefficient $D_{H}$ of free protons, the flux equation

$$
\bar{J}_{c a t}=-D_{w} \operatorname{grad} C_{c a t}
$$

is obtained [19]. Here,

$$
D_{w}=\frac{K_{a}}{C_{r}+K_{a}} D_{H} \text {, at } C_{C a t} \rightarrow C_{r}
$$

$\bar{J}_{c a t}$ - diffusion flux of cations, $K_{a}$ - dissociation constant of phenol $\mathrm{OH}$ groups in a polymer, $C_{r}$ - general concentration of fixed ionogens (ionized and not ionized hydroxyl groups) in a polymer.

Since swelling and hydration values of studied polymer 2 upon conversion (II) remain constant $\left(30 \mathrm{~mol} \mathrm{H}_{2} \mathrm{O}\right.$ per 1 equiv. of total capacity of polymer), it can be to assumed that the effective diffusion coefficient in polymer $D_{w}$ in equation (3) is 
constant. Let us calculate its value. We take $D_{H}=10^{-9} \mathrm{~m}^{2} / \mathrm{c}[19,20] ; C_{r}=1 \times 10^{3} \mathrm{~mol} / \mathrm{m}^{3}$. The value of $K_{a} \approx 10^{-6} \mathrm{~mol} / \mathrm{m}^{3}$ is obtained by the data [7] of potentiometric titration of sulfonated polymers 1 and 2 . Thus $D_{w}$ which was calculated using equation (4) is equal to $10^{-18} \mathrm{~m}^{2} / \mathrm{s}$.

\subsubsection{Spherical layer model for particle of polymer 1 or 2}

We assume that the spherical particle of polymer 1 or 2 should consist of a set of spherical layers. $\mathrm{SO}_{3}^{-} \mathrm{Cat}^{+} \mathrm{groups}$ are located on the outer surface of each spherical layer while phenol $\mathrm{OH}$ groups nearest to them are on its inner surface (Figure 2). The diffusion flux of $\mathrm{Cat}^{+}$through a spherical layer passes the distance between $\mathrm{SO}_{3}^{-} \mathrm{Cat}^{+}$and $\mathrm{phenol} \mathrm{OH}$ groups (Figure 2).

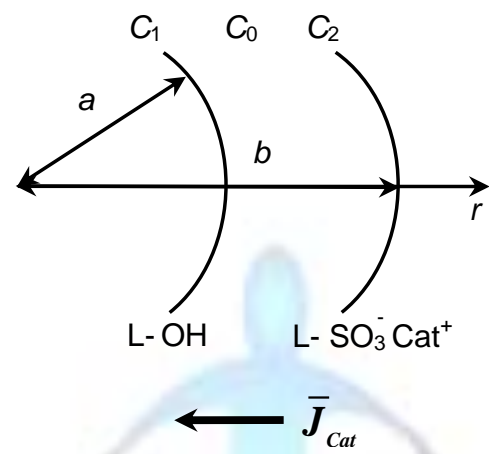

Fig 2: The diffusion flux of $\mathrm{Cat}^{+}$through a spherical layer in bifunctional polymer 2

For non-steady state the solution of diffusion equation (1) can be obtained by Laplace transforms or a method of separation of variables [21] in case diffusion coefficient is constant. If the surface $r=a$ is maintained at $C_{1}$, and and $r=b$ at $C_{2}$, and the region $a \leq r \leq b$ is initially at $C_{0}$, the solution [21] of equation (1) is the expression

$$
\begin{aligned}
& C=\frac{a C_{1}}{r}+\frac{\left(b C_{2}-a C_{1}\right)(r-a)}{r(b-a)}+\frac{2}{r \pi} \sum_{n=1}^{\infty} \frac{b\left(C_{2}-C_{0}\right) \cos n \pi-a\left(C_{1}-C_{0}\right)}{n} \times \\
& \times \sin \frac{n \pi(r-a)}{b-a} \exp \left\{-D n^{2} \pi^{2} t /(b-a)^{2}\right\} .
\end{aligned}
$$

$M_{t}^{*}$ denotes the total amount of $\mathrm{Cat}^{+}$, which accumulates in the layer after time $t . M_{t}^{*}$ was obtained [21] by integrating of expression (5). When $C_{0}=0, C_{1}=0$

$$
M_{t}^{*}=\frac{4 \pi}{3}(b-a) C_{2}\left[\left(b^{2}+\frac{a b}{2}\right)-\frac{6}{\pi^{2}} \sum_{n=1}^{\infty}\left\{b^{2}-a b \cos n \pi\right\} \times \frac{\exp \left\{-D_{w} n^{2} \pi^{2} t /(b-a)^{2}\right\}}{n^{2}}\right] .
$$

If $M_{\infty}^{\prime}$ denotes the quantity of Cat $^{+}$, which has entered the layer after infinite time, then

$$
M_{\infty}^{*}=C_{2} \frac{4 \pi}{3}(b-a)\left(b^{2}+\frac{a b}{2}\right)
$$

Based on the proposed model, the transformation degree in the spherical particle consisting of a set of spherical layers and the transformation degree in the spherical layer are the same. The transformation degree in time $t$ is

$$
F=\frac{M_{t}}{M_{\infty}}=\frac{M_{t}^{*}}{M_{\infty}^{*}}=1-\frac{6}{\pi^{2}} \sum_{n=1}^{\infty} \frac{\left(b^{2}-a b \cos n \pi\right)}{\left(b^{2}+\frac{a b}{2}\right)} \times \frac{\exp \left\{-D_{w} n^{2} \pi^{2} t /(b-a)^{2}\right\}}{n^{2}} .
$$

Equation (8) is transformed into equation (2) if $a=0 ; b=r_{0}$.

The dependences of the transformation degree from $\left(D_{w} t /(b-a)^{2}\right)^{1 / 2}$ are shown in Figure 3 for different values of $b / a$. The top curve corresponds to solid sphere $(a=0)$, bottom - to plane sheet $(b / a=1, r>>(b-a))$. As can be seen from the Figure 3, the bottom curve describes the behavior of our system, it covers the whole range of experimental data of cation sorption from alkaline solutions with the participation of the hydroxyl groups of sulfonated polymer 2 . Consider the data of ion exchange kinetics at polymer 2 based on cis-tetraphenylmetacyclophanoctol according to the theory of diffusion in a plane sheet. 


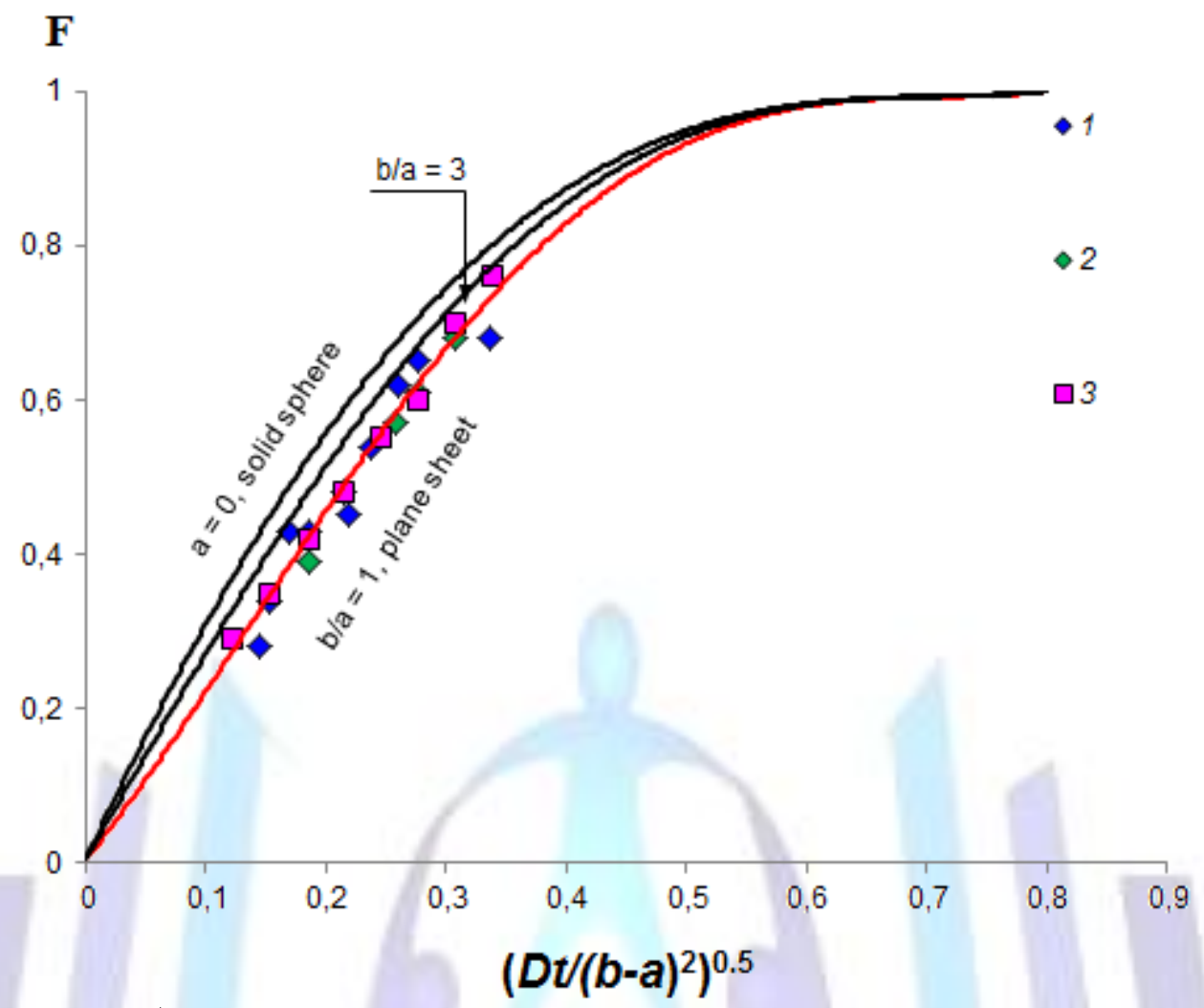

Fig 3: $F$ vs $\left(D_{w} t /(b-a)^{2}\right)^{1 / 2}$. Curves - calculations by equation (8); dots - experimental data: 1 - cation sorption from $0.1 \mathrm{~mol} / \mathrm{dm}^{3} \mathrm{NaOH}$ solutions; 2 - cation sorption from $0.03 \mathrm{~mol} / \mathrm{dm}^{3} \mathrm{NaOH}$ solutions; 3 - cation sorption from $0.05 \mathrm{~mol} / \mathrm{dm}^{3} \mathrm{LiOH}$ solutions by bifunctional polymer 2 (process (II))

\subsubsection{Diffusion in a plane sheet for polymer particle}

If $r \gg>(b-a)$, the spherical layer of polymer 2 can be regarded as a plane sheet or membrane, in which $\mathrm{SO}_{3}^{-} \mathrm{Cat}^{+}$groups are located on the outer surface of a plane sheet while phenol $\mathrm{OH}$ groups nearest to them are on its inner surface. Consider the case of diffusion through a plane sheet or membrane of thickness $/$ with constant diffusion coefficient $D_{\mathrm{w}}$, whose surfaces, $x=0, x=I$, are maintained at constant concentrations $C_{1}, C_{2}$ respectively, a plane sheet is set initially at a uniform concentration $C_{0}$.

It was shown [21] for non-steady state that the concentration of the species in a plane sheet is given by

$$
\begin{aligned}
C=C_{1} & +\left(C_{2}-C_{1}\right) \frac{x}{I}+\frac{2}{\pi} \sum_{n=1}^{\infty} \frac{C_{2} \cos n \pi-C_{1}}{n} \sin \frac{n \pi x}{/} \exp \left(-D_{w} n^{2} \pi^{2} t / I^{2}\right)+ \\
& +\frac{4 C_{0}}{\pi} \sum_{m=1}^{\infty} \frac{1}{2 m+1} \sin \frac{(2 m+1) \pi x}{/} \exp \left(-D_{w}(2 m+1)^{2} \pi^{2} t / I^{2}\right)
\end{aligned}
$$

According to [21] the transformation degree in time $t$ is

$$
F=\frac{M_{t}^{*}}{M_{\infty}^{*}}=1-\frac{8}{\pi^{2}} \sum_{n=0}^{\infty} \frac{1}{(2 n+1)^{2}} \exp \left\{-D_{n}(2 n+1)^{2} \pi^{2} t / I^{2}\right\}
$$

Note that equation (8) is transformed into equation (10) if $r>>(b-a)$. The experimental data $F(t)$ are well approximated by the equations (8) or (10), if $D_{w}$ is equal to $10^{-18} \mathrm{~m}^{2} / \mathrm{s}$.

\subsection{Process (III). Cation - exchange on phenol hydroxyl groups of polymer 4}

As was shown [19] the rates of ion exchange processes with participation of weakly acid ion exchangers are controlled either by interdiffusion of $\mathrm{H}^{+}$ions and sorbed Cat ${ }^{+}$cations or by diffusion of $\mathrm{OH}^{-}$anions in polymer. In this case the rate of the process (III) is controlled by diffusion of $\mathrm{OH}^{-}$anions in a polymer 4. The known [19] equation (11)

$$
F=1-\left\{\sin \left[\frac{1}{3} \arcsin \left(1-12 \frac{D_{O H} C_{O H}^{\circ} t}{C_{r} r_{0}^{2}}\right)\right]+\frac{1}{2}\right\}^{3}
$$


describes experimental data [14] of ion-exchange rates in polymer 4 in all researched range of concentrations. Here $D_{O H}-$ diffusion coefficient of $\mathrm{OH}^{-}$anions in polymer, $C_{O H}^{\circ}$ - concentration of $\mathrm{OH}^{-}$anions on the surface of a spherical particle of a polymer.

\section{RESULTS AND DISCUSSION}

According to equation (3), at constant diffusion coefficient, the diffusion flux depends only on concentration gradient. In monofunctional cation exchangers the value of the concentration gradient is determined by the change in the concentration of a diffusing component at a macroscopic distance from the outer surface of the ion exchange particle to its center. In bifunctional cation exchangers (polymer 1 and polymer 2) the cation diffusion flux passes the distance between $\mathrm{SO}_{3}^{-} \mathrm{Cat}^{+}$and phenol $\mathrm{OH}$ groups. It is considerably less than the dimension of the ion exchange particle. In the repeating unit of polymer 2 the calculated distance is several nanometers (Figure 4). Based on the proposed model the length of diffusion path, i.e. $(b-a)$ in equation (8), or I in equation (10) equal to $30 \mathrm{~nm}$. Large concentration gradient will increase the rate of the process (II).

Half-transformation periods of time $(t$ at $F=0.5$ ) calculated from the experimental data [14-16] are given in the Table 1 . As we seen from the table the process (I) of ion exchange $\mathrm{H}^{+}-\mathrm{Cat}^{+}$with participation of sulfonic acid groups of polymer 2 has the highest rate, the process (III) of sorption of cations $\mathrm{Cat}^{+}$from alkaline solutions with participation phenol $\mathrm{OH}$ groups of polymer 4 has the lowest rate.

Table1. Half-transformation periods of ion exchange in cation exchangers based on cis-metacyclophanoctol

\begin{tabular}{|c|c|c|c|}
\hline Polymers & Process & lonogenic groups & $\begin{array}{c}\boldsymbol{t}, \mathbf{s} \\
\text { at } \boldsymbol{F}=\mathbf{0 . 5}\end{array}$ \\
\hline Bifunctional polymer 2 & I & strongly acidic $\mathrm{SO}_{3} \mathrm{H}$ groups & 16 \\
\hline Bifunctional polymer 2 & II & strongly acidic $\mathrm{SO}_{3} \mathrm{H}$ groups, weakly acidic phenol OH groups & 50 \\
\hline Monofunctional polymer 4 & III & weakly acidic phenol OH groups & 9500 \\
\hline
\end{tabular}

Comparing the rates of ion exchange processes (II) and (III) with participation of weakly dissociating ionogenic groups at bifunctional and monofunctional cation exchangers, we find out the nanoreactor effect that consists in hundredfold increase in ion exchange rate on bifunctional cation exchangers. The cup of bifunctional cistetraphenylmetacyclophanoctol, which contains as strongly acidic $\mathrm{SO}_{3} \mathrm{H}$ groups and weakly acidic phenol $\mathrm{OH}$ groups (Figure 4) immobilized in the network polymer phase, acts as nanoreactor.

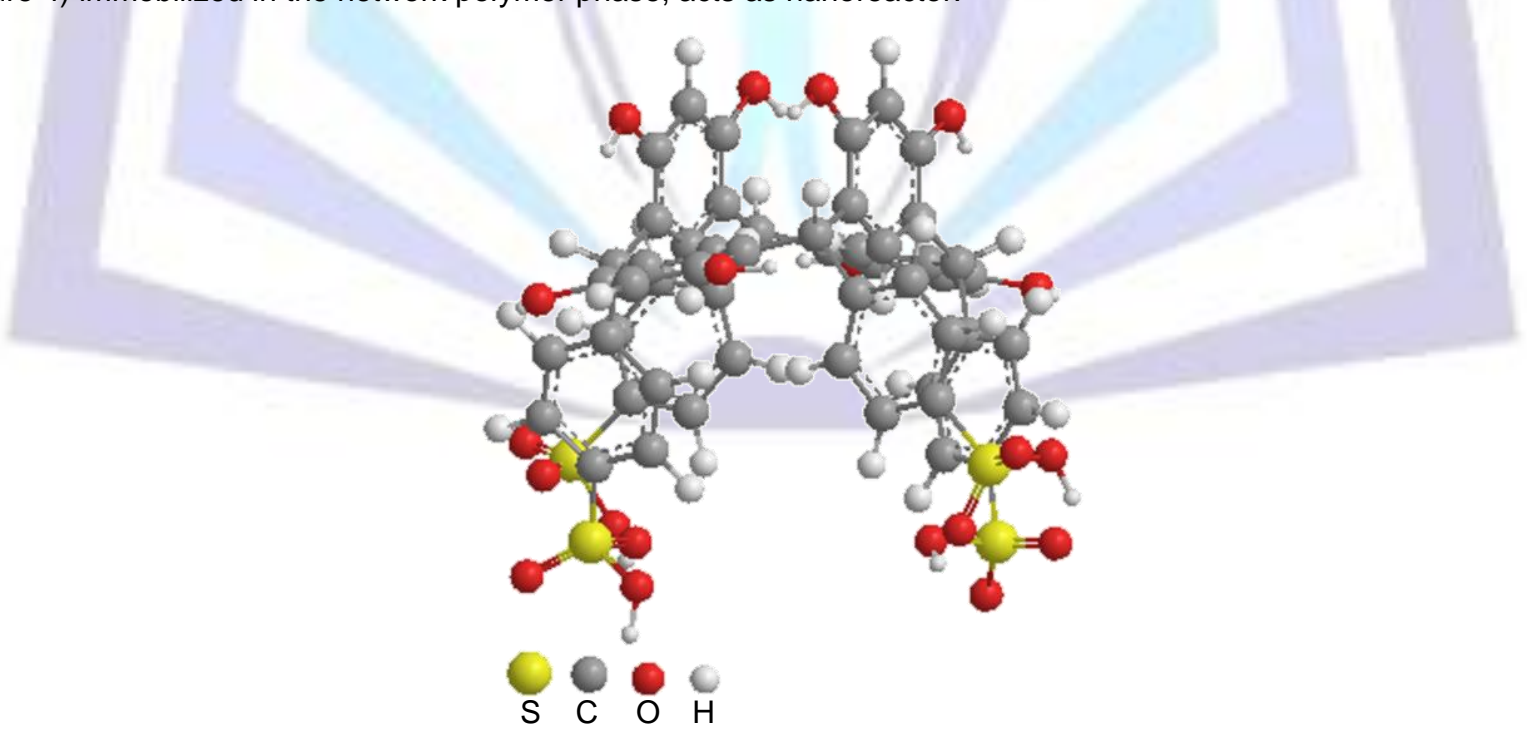

Fig 4: The repeating unit of polymer 2 molecular structure minimized by the semiempirical PM6 method within the MOPAC 2009 program

\section{CONCLUSION}

The solutions of the fundamental differential equation of cation diffusion were used for investigation of ion exchange kinetics in sulfonated polymers based on cis-metacyclophanoctol. The mathematical model explaining the nanoreactor effect in bifunctional cation exchangers was proposed. It predicts considerable improvement of the kinetic characteristics 
of cation exchangers containing weakly dissociating ionogenic groups when strong acidic functional groups are introduced into these cation exchangers. This effect holds good for both bifunctional polymers based on derivatives of cismetacyclophanoctol and other bifunctional cation exchangers (for example Amberlite IRA-100 type) for producing ionexchange membranes and selective sorbents.

\section{ACKNOWLEDGEMENTS}

This work was supported by the Russian Foundation for Basic Research (Project No: 07-03-96030).

\section{REFERENCES}

[1] Juan-Alcaniz, J., Ramos-Fernandez, E.V., Kapteijn, F., Gascon, J. 2013. MOFs as Nano-reactors. In book Metal Organic Frameworks as Heterogeneous Catalysts.

[2]. Hogberg, A. G. S. Cyclooligomeric phenol-aldehyde condensation products. 2. Stereoselective synthesis and DNMR study of two 1,8,15,22-tetraphenyl[14]metacyclophan-3,5,10,12,17,19,24,26-octols. Journal of the American Chemical Society. 1980, V.102, №19, 6046-6050.

[3] Zamaraev, K.I. Perspectives in catalysis: via studies on molecular level to new industrial catalysts and processes. Usp. Khim. 1993, V. 62, №11, 1051-1063.

[4] Alexandratos, S. D., Natesan, S. Synthesis and ion binding affinities of calix[4]arenes immobilized on cross-linked polysterene. Macromolecules. 2001, V. 34, № 2, 206-210.

[5] Altshuler, H., Ostapova, E., Fedyaeva, O., Sapozhnikova, L., Altshuler, O. Novel network polymers based on calixresorcinarenes. Macromolecular Symposia. 2002. V. 181, № 1, 1-4.

[6] Altshuler, H., Sapozhnikova, L., Ostapova, E., Fedyaeva, O., Altshuler, O. Cationites based on calyx[4]resorcinarene derivatives. Solvent Extraction and Ion Exchange. 2002, V. 20, № 2., 263-271.

[7] Altshuler, O., Sapozhnikova, L., Altshuler, H. New sulfonato-containing network polymers based on immobilized cismetacyclophan-3, 5, 10, 12, 17, 19, 24, 26 - octols. Polymer Science. Ser. A. 2007, V. 49, №7, 795-801.

[8] Altshuler, H., Abramova, L., Altshuler, O. Russian Federation Patent №: 2291171.

[9] Sapozhnikova, L., Altshuler, O., Malyshenko, N., Shkurenko, G., Ostapova, E., Tryasunov, B., Altshuler, H. Solid phase nanoreactor based on polycalix[4]resorcinarene for catalytic processes with participation of hydrogen and oxygen. International Journal of Hydrogen Energy. 2011, V. 36, №. 1, 1259-1263.

[10] Altshuler, H. N., Fedyaeva, O. N., Sapozhnikova, L. A., Ostapova, E.V. Novel polymer based on 1,8,15,22tetramethyl[14] metacyclophan-3-,5,10,12,17,19,24, 26-oktol. Polymer Science. Ser. B. 2001, V. 43, № 3-4, $112-115$.

[11] Ostapova, E. V., Altshuler, O. H., Sapozhnikova, L. A., Altshuler, H. N. Interaction of calixarene-containing polymers with aqueous ammonia. Russian Journal of Physical Chemistry A. 2003, V. 77, № 5, 814-818.

[12] Altshuler, H., Sapozhnikova, L., Ostapova, E., Altshuler, O. The thermodynamic characteristics of ion exchange in a sulfonated polymer based on cis-tetraphenylcalix[4]resorcinarene. Russian Journal of Physical Chemistry A. 2007, V. 81, № 7, 1011-1015.

[13] Altshuler, H. N., Ostapova, E. V., Sapoznikova, L. A., Altshuler, O. H. Thermodynamics of ion exchange in a sulfonated polymer based on cis-tetraphenylmetacyclophanoctol. Journal of Thermal Analysis and Calorimetry. 2008, V. 92, №3, 665-669.

[14] Al'tshuler, G.N. and Fedyeva, O. N. Kinetics of cation exchange on calixarencontaining polymer. Zh. Fiz. Khim. 2001, V.75, №11, 2088-2089.

[15] Altshuler, H., Malyshenko, N., Shkurenko, G. Kinetics of cation exchange on sulfonic polymer based on immobilized cis-tetraphenylcalix[4]resorcinolarene. Russian Journal of Applied Chemistry. 2007, V. 80, № 10, 1737-1740.

[16] Altshuler, O. H., Malyshenko, N. V., Shkurenko, G. J., Altshuler, H. N. Solid-phase nanoreactor based on calix[4]reasorcinarene: Gel diffusion kinetics of ion exchange. Theoretical Foundations of Chemical Engineering. 2009. V. 43, № 1, 43-49.

[17] Boyd, G., Adamson, A., Myers, L. The exchange adsorption of ions from aqueous solutions by organic zeolites. II. Kinetics. Journal of the American Chemical Society. 1947, V. 69, № 11, 2836-2848.

[18] Helfferich, F. 1959. Ionenaustauscher.

[19] Helfferich, F. lon-exchange kinetics. V. Ion-exchange accompanied by reactions. The Journal of Physical Chemistry. 1965, V. 69, № 4, 1178-1187.

[20] Boyd, G. E., Soldano B. A. Self-diffusion of cations in and through sulfonated polystyrene cation-exchange polymers. Journal of the American Chemical Society. 1953, V. 75. № 24, 6091-6099.

[21] Crank, J. 1975. The Matematics of Diffusion. 